\title{
Introduction to the special issue on the 2012 EUCOMES European Conference on Mechanism Science
}

(C) Higher Education Press and Springer-Verlag Berlin Heidelberg 2013

EUCOMES 2012 has been the fourth event of the series for EUCOMES (European Conference on Mechanism Science). EUCOMES was started as a conference initiative mainly for the European community working in Machine and Mechanism Science in order to facilitate aggregation and sharing interests for a better collaboration and activity visibility mainly but not only within European frames. The series was started in 2006 and the previous EUCOMES conferences were successfully held in Innsbruck, Austria (2006), Cassino, Italy (2008), and Cluj-Napoca, Romania (2010). EUCOMES 2012 was held in Santander, Spain from 18 to 22 September 2012. EUCOMES 2012 was organized by the University of Cantabria under the patronage of IFToMM, the International Federation for the Promotion of Mechanism and Machine Science.

The EUCOMES 2012 collected the most recent research results in the mechanism science, intended to reinforce and improve mechanical systems in a variety of applications in daily life and industry. The issues addressed were on Theoretical Kinematics, Computational Kinematics, Mechanism Design, Mechanical Transmissions, Linkages and Manipulators, Mechanisms for Biomechanics, Mechanics of Robots, Dynamics of Multi-Body Systems, Control Issues of Mechanical Systems, Novel Designs, Teaching Methods, History of Mechanism Science and Industrial and Non-Industrial Applications.

EUCOMES 2012 received more than 90 papers and after careful review with at minimum two reviews for each paper, 83 papers have been considered acceptable for conference presentation and publication in a proceedings book published by Springer in the book series on MMS.

This special journal issue has been obtained as a result of a selection and second review process, but all the papers that were accepted for EUCOMES 2012 were of good quality with interesting contents suitable for Journal publication and it has been hard to decide for the selection. Perhaps some papers did not received due attention for this special issue from reviewers but we hope that the authors have decided for a submission to a journal yet.

We would like to express grateful thanks to IFToMM, the Spain IFToMM National Committee, the members of the International Scientific Committee for the EUCOMES Conference for their co-operation: Marco Ceccarelli (Univ. Cassino, Italy), Burkhard Corves (Univ. Aachen, Germany), Paulo Flores (Univ. Minho, Portugal), Manfred Husty (Univ. Innsbruck, Austria), Jean-Pierre Merlet (INRIA, France), Doina Pisla (Tech. Univ. Cluj-Napoca, Romania), Fernando Viadero (Univ. Cantabria, Spain), and Teresa Zielinska (Warsaw Tech. Univ., Poland).

We thank the authors who have contributed excellent papers on different subjects, covering many fields of Mechanism Science. We are grateful to the reviewers for the time and effort they spent evaluating the papers.

We thank the University of Cantabria for hosting the EUCOMES 2012 Conference and colleagues of the Local Organizing Committee and the sponsors of EUCOMES 2012 conference for their help as the Spanish Association of Mechanical Engineering (AEIM).

Received December 30, 2012

Marco CECCARELLI ( $(\bowtie)$

University of Cassino and South Latium, Cassino 03043, Italy

E-mail: ceccarelli@unicas.it

Fernando VIADERO

University of Cantabria, Santander 39005, Spain 
We believe that this journal special issue on EUCOMES 2012 can be an interesting reference for the European activity in the fields of Mechanism and Machine Science as wells as a source of inspirations for future works and developments. 